\title{
Smoking cessation and survival among people diagnosed with non-metastatic cancer
}

Tracey E. Barnett ${ }^{1 *}$ D, Yan Lu², Aaron W. Gehr ${ }^{2}$, Bassam Ghabach ${ }^{3}$ and Rohit P. Ojha ${ }^{1,4}$

\begin{abstract}
Background: We aimed to estimate the effects of smoking cessation on survival among people diagnosed with cancer.

Methods: We used data from a Comprehensive Community Cancer Program that is part of a large urban safety-net hospital system. Eligible patients were diagnosed with primary invasive solid tumors between 2013 and 2015, and were current smokers at time of diagnosis. Our exposure of interest was initiation of smoking cessation within 6 months of cancer diagnosis. We estimated inverse probability weighted restricted mean survival time (RMST) differences and risk ratio (RR) for all cause 3-year mortality.

Results: Our study population comprised 369 patients, of whom $42 \%$ were aged $<55$ years, 59\% were male, $44 \%$ were racial/ethnic minorities, and 59\% were uninsured. The 3-year RMST was 1.8 ( $95 \% \mathrm{CL}:-1.5,5.1)$ months longer for individuals who initiated smoking cessation within 6 months of cancer diagnosis. The point estimate for risk of 3-year mortality was lower for initiation of smoking cessation within 6 months of diagnosis compared with no initiation within 6 months ( $R R=0.72,95 \% \mathrm{CL}: 0.37,1.4)$.

Conclusions: Our point estimates suggest longer 3-year survival, but the results are compatible with 1.5 month shorter or 5.1 longer 3-year overall survival after smoking cessation within 6 months of cancer diagnosis. Future studies with larger sample sizes that test the comparative effectiveness of different smoking cessation strategies are needed for more detailed evidence to inform decision-making about the effect of smoking cessation on survival among cancer patients.

Implications for Cancer survivors: The benefits of smoking cessation after cancer diagnosis may include longer survival, but the magnitude of benefit is unclear.
\end{abstract}

Keywords: Cancer, Smoking, Cessation, Survival

\section{Background}

Smoking is associated with adverse outcomes including mortality for people diagnosed with cancer [1-6]. The National Comprehensive Cancer Network Clinical Practice Guidelines thus recommends smoking cessation for

\footnotetext{
* Correspondence: Tracey.Barnett@unthsc.edu

${ }^{1}$ School of Public Health, University of North Texas Health Science Center, 3500 Camp Bowie Blvd., Fort Worth, TX 76107, USA

Full list of author information is available at the end of the article
}

patients diagnosed with cancer at any stage [7], but 5083\% continue smoking after cancer diagnosis [8]. Despite certain substantiated benefits of smoking cessation [6], insufficient direct evidence is available about whether smoking cessation improves survival among people diagnosed with cancer [2, 9-11]. For example, a 2019 Cochrane Systematic Review [12] did not identify any randomized controlled trials (RCTs) that reported the effect of smoking cessation interventions on lung cancer

(c) The Author(s). 2020 Open Access This article is licensed under a Creative Commons Attribution 4.0 International License, which permits use, sharing, adaptation, distribution and reproduction in any medium or format, as long as you give appropriate credit to the original author(s) and the source, provide a link to the Creative Commons licence, and indicate if changes were made. The images or other third party material in this article are included in the article's Creative Commons licence, unless indicated otherwise in a credit line to the material. If material is not included in the article's Creative Commons licence and your intended use is not permitted by statutory regulation or exceeds the permitted use, you will need to obtain permission directly from the copyright holder. To view a copy of this licence, visit http://creativecommons.org/licenses/by/4.0/. The Creative Commons Public Domain Dedication waiver (http://creativecommons.org/publicdomain/zero/1.0/) applies to the data made available in this article, unless otherwise stated in a credit line to the data. 
survival. Particularly informative would be evidence related to the magnitude of survival benefit related to early smoking cessation. Nevertheless, an adequately powered RCT with sufficient longitudinal follow-up to assess the effects of smoking cessation on survival may be infeasible. Alternate approaches should be explored to address this gap in the evidence.

The target trial framework is a recent advancement to facilitate addressing questions using observational data that may be infeasible through RCTs [13]. This framework uses strengths of RCTs to guide the design of observational studies. In particular, the target trial framework can help reduce the effect of biases from misaligned time zero, which can often be more severe than unmeasured confounding [13-16]. Prior studies that used this framework reported similar estimates between observational studies and RCTs that assessed the effect of antiretroviral treatments on HIV outcomes [17], or the effect of statins on disease prevention [18]. In the absence of an RCT, this approach could help generate useful evidence about the effects of smoking cessation among people diagnosed with cancer. Therefore, we aimed to assess the effect of smoking cessation on survival among people diagnosed with cancer using a target trial framework.

\section{Methods}

\section{Setting}

The JPS Oncology and Infusion Center is a Comprehensive Community Cancer Program that has been accredited by the Commission on Cancer since 2010. The Oncology and Infusion Center is part of JPS Health Network, a large urban safety-net system that serves Tarrant County, TX. The network is a primary source of care for underserved and vulnerable populations, which includes individuals who are uninsured, under-insured, racial/ethnic minorities, immigrants, disabled, homeless, and inmates [19-21].

\section{Data sources and eligibility criteria}

We linked data between the JPS Oncology and Infusion Center Registry and electronic health records from the entire JPS Health Network, which allowed for ascertaining additional health information documented during interactions with the healthcare system prior to and following cancer diagnosis. Patients eligible for our analyses were aged $\geq 18$ years, diagnosed with a first primary invasive solid tumor between 2013 and 2015, received all or part of the first course treatment at JPS Oncology and Infusion Center, and were current smokers at the time of cancer diagnosis (i.e., on or within 30 days before the date of cancer diagnosis). We excluded patients with metastatic cancers because smoking cessation may not be a priority when life expectancy is limited.

\section{Outcomes}

Our primary outcome of interest was 3-year all-cause mortality. Vital status was ascertained through the institutional registry from JPS Oncology and Infusion Center. The cancer registrars routinely check multiple sources of mortality information (e.g., Bureau of Vital Statistics, Social Security Death Index, Texas Obituaries, Fort Worth Star Telegram Obituaries, Tarrant County Medical Examiner, JPS electronic medical records, etc.) to maintain at least $90 \%$ follow-up at 5 years for Commission on Cancer accreditation.

\section{Intervention and follow-up}

We defined intervention as initiation of smoking cessation within 6 months of cancer diagnosis, which was based on the date of provider-documented change in smoking status from current to former. Baseline (i.e., time zero) for the first trial was thus the date of cancer diagnosis and patients were followed until death, loss to follow-up, or end of study, whichever occurred first. Patients were classified as initiating the intervention if smoking cessation was documented within the first 30 days after cancer diagnosis and not initiating the intervention if smoking cessation was not documented within the first 30 days after cancer diagnosis. We sequentially applied the eligibility criteria and intervention definition for the 5 successive 30-day intervals (i.e., through 180 days after cancer diagnosis) to generate a total of 6 trials, where baseline for each trial was the beginning of each 30-day interval. Consequently, patients could have been eligible for up to 6 trials but were no longer eligible for subsequent trials if smoking cessation was initiated in a previous trial. We did not have sufficient information to accurately determine duration of smoking cessation, which precluded an adherenceadjusted (i.e., per protocol) analysis.

\section{Data analysis}

We pooled data from all 6 sequential trials and used a marginal structural model [22] with pseudo-observations $[23,24]$ to estimate risk ratio (RR) and restricted mean survival time (RMST) difference for 3-year mortality. The estimates generated from this approach are analogous to an intention to treat estimate from a pragmatic trial [13]. The pooling of sequential trials also allows for reducing variance when few initiators of the intervention (smoking cessation in our study) are observed. In addition, a critical advantage of the pseudo-observation approach is that the estimates are not sensitive to the assumption of proportional hazards during follow-up, as in Cox proportional hazard regression [25]. RRs and RMST differences are also more easily interpreted by patients and providers than hazard ratios, which could facilitate shared decision-making [25-28]. 
Specifically, we fit a logistic regression model to compute stabilized inverse probability weights [29] $($ mean $=$ 1.0, range $=0.29-4.4$ ) of smoking cessation within 6 months. These weights were conditioned on a minimal sufficient set of covariates to reduce confounding bias identified by applying the back-door criterion to a directed acyclic graph of dependencies between smoking cessation and mortality (Supplementary Figure S1). The stabilized inverse probability weights were thus conditioned on baseline measurements of age (18-44, 45-54, $55-64$, or $>65$ years), gender, race/ethnicity (non-Hispanic White, non-Hispanic Black, Hispanic, and Other), cancer type (smoking- and non-smoking-related cancers [30]), cancer stage (Surveillance, Epidemiology, and End Results summary stage categories of localized or regional), packs of cigarettes per day ( $\leq 1$ or $>1$ packs per day), alcohol use (current and formal user, or never user), insurance coverage (uninsured, public insurance, private insurance, and other insurance), comorbidity (NCI Comorbidity Index [31] score categorized as 0 , or > 0 ), BMI (BMI $<25,25 \leq \mathrm{BMI}<30$, or $\mathrm{BMI} \geq 30$ ), and marital status (single/never married, married, separated/ divorced/widowed). We applied these weights in a generalized linear model with pseudo-observations for the survival function at 3 years and log link to estimate RRs comparing initiation and non-initiation of smoking cessation within 6 months to no smoking cessation within 6 months. In addition, we applied these weights in a generalized linear model with pseudo-observations for restricted mean survival function at 3 years to estimate RMST differences between initiation and non-initiation of smoking cessation within 6 months. RMST provides an absolute measure of differences in survival time at the specified time horizon. For example, an estimate of 1.5 when comparing initiation and non-initiation of smoking cessation at a 3-year time horizon would be interpreted as a 1.5 month longer mean survival after smoking cessation at 3-years of follow-up. We estimated 95\% compatibility limits (CL) [32] for RR and RMST difference based on clustered standard errors to account for individuals who contributed information to multiple trials. We lacked sufficient sample size to explore effects by cancer type.

\section{Sensitivity analysis}

Unmeasured confounding is a threat to the validity of observational studies. Consequently, we explored the sensitivity of our estimates to unmeasured confounding by computing E-values [33]. The E-value represents the required effect of the unmeasured confounder (or matrix of confounders) on both smoking cessation within 6 months and mortality, conditional on measured covariates, to nullify our estimates.

\section{Results}

Our eligible population comprised 409 cancer patients, of whom 369 patients with complete covariate information were included in our analysis (Fig. 1). Evaluable patients contributed 1654 observations after pooling the 6 sequential trials (Supplementary Table S2). Table 1 summarizes the characteristics of the study population. Briefly, 78\% were aged $45-64$ years old, 59\% were male, $44 \%$ were racial/ethnic minorities, $59 \%$ were uninsured, and $57 \%$ were diagnosed with localized stage cancers. In addition, 51\% smoked more than one pack of cigarettes per day at the time of diagnosis, $31 \%$ initiated smoking cessation within 6 months of diagnosis, and 22\% died by the end of 3-year follow-up after cancer diagnosis. The median follow-up time was 15 months (interquartile range: $5.8-22$ months).

Figure 2 illustrates the marginal survival curves for patients who initiated or did not initiate smoking cessation within 6 months of cancer diagnosis. Given 3 years follow-up, the average survival time was 1.8 (95\% CL: $1.5,5.1$ months) months longer for individuals who initiated smoking cessation within 6 months of cancer diagnosis (Table 2). Table 2 also summarizes the effect of initiating smoking cessation within 6 months of cancer diagnosis on 3-year mortality. The risk of 3-year allcause mortality was $28 \%$ lower relative to no initiation of smoking cessation within 6 months of cancer diagnosis, but our estimates could be compatible with up to a $63 \%$ lower risk or $40 \%$ higher risk ( $R R=0.72$; $95 \%$ CL: 0.37 , 1.4). Figure 3 illustrates the range of estimates for unmeasured confounding that could explain our results. The E-value for the point estimate was $\mathrm{RR}=2.1$.

\section{Discussion}

Smoking cessation is considered beneficial for general health, but the magnitude of survival benefits for people diagnosed with cancer is unclear. In particular, the interval of smoking cessation after cancer diagnosis is important considering potentially long smoking histories among people diagnosed with cancer [34]. Our point estimates suggest longer survival and lower 3-year mortality after smoking cessation within 6 months of cancer diagnosis compared with no smoking cessation within 6 months, but this estimate is imprecise and compatible with strong beneficial effects or modest harmful effects. For example, smoking cessation within 6 months of cancer diagnosis prolonged mean survival by 1.8 months after 3 years of follow-up, but this estimate was compatible with 1.5 months shorter or 5.1 months longer survival compared with no smoking cessation within 6 months of cancer diagnosis.

Several limitations should be considered when interpreting our results. A key assumption of inference to consider in our analyses is exchangeability (i.e. no 


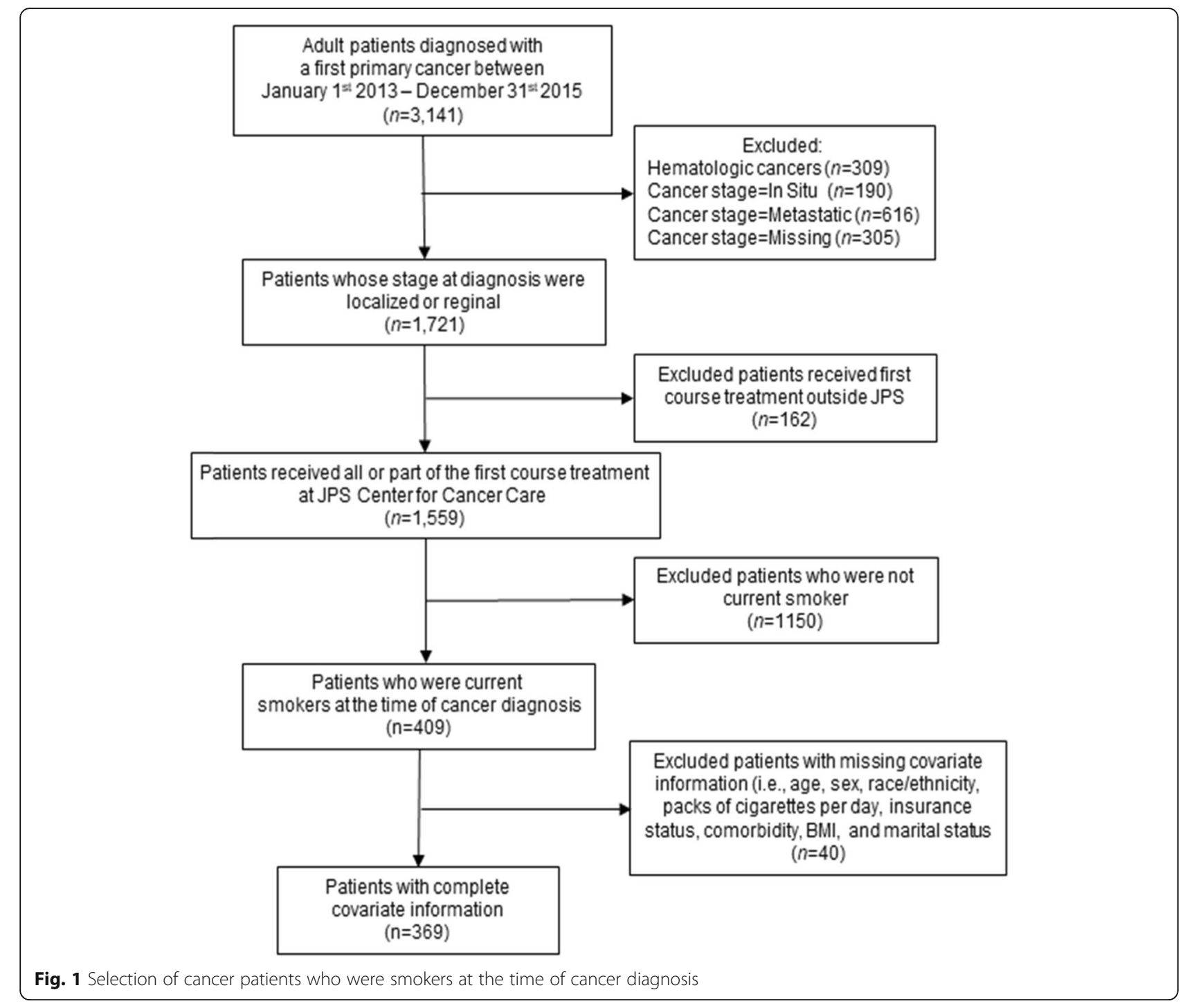

confounding) [35]. We adjusted for key measured preexposure common causes of smoking cessation and mortality, but bias from unmeasured confounding is possible. For example, psychological distress may affect smoking cessation and mortality, but information about psychological distress was not uniformly available. We estimated the E-value [33] to assess the robustness of the point estimate to unmeasured confounding. The Evalue was 2.1, which indicates that the risk ratio for the unmeasured covariate(s) in relation to both the exposure and outcome must be at least 2.1 to nullify the mortality reduction indicated by the point estimate after smoking cessation. Despite plausibility, we question whether this magnitude of unmeasured confounding is possible given the extent of covariate adjustment. In addition, alignment of time zero, based on the design of our study, can further attenuate the effect of confounding [13-16].
Another key assumption for inference is consistency [36], which requires unambiguous definition of the exposure. We defined the period during which smoking cessation occurred, but we lacked sufficient information to define precisely how smoking cessation was achieved. For example, we are unclear whether patients used nicotine replacement therapy, counseling, or other interventions. Our estimates thus represent the maximum potential effect of smoking cessation but not necessarily a single intervention. In addition, our estimates are analogous to an intention to treat effect. Differences in adherence to smoking cessation could result in over- or underestimation of effect (i.e. per protocol effect), but inconsistent post-smoking cessation data precluded estimating an adherence-adjusted estimate.

Prior studies [37-42] did not address the effect of smoking cessation within a well-defined interval after cancer diagnosis, which could be useful for informing 
Table 1 Characteristics of adult cancer patients who were diagnosed with a first primary invasive non-metastatic solid malignancy between 2013 and 2015 and were smokers at baseline

\begin{tabular}{|c|c|c|c|}
\hline Characteristics & $\begin{array}{l}\text { All patients }(n=369) \\
n(\%)\end{array}$ & $\begin{array}{l}\text { Patients who quit within } 6 \text { months } \\
\text { of diagnosis }(n=116) \\
n(\%)\end{array}$ & $\begin{array}{l}\text { Patients who did not quit within } \\
6 \text { months of diagnosis }(n=253) \\
n(\%)\end{array}$ \\
\hline \multicolumn{4}{|l|}{ Age } \\
\hline $18-44$ years & $50(14)$ & $15(13)$ & $35(14)$ \\
\hline $45-54$ years & $107(29)$ & $30(26)$ & $77(30)$ \\
\hline $55-64$ years & $179(49)$ & $60(52)$ & $119(47)$ \\
\hline 65 years and up & $33(8.9)$ & $11(9.5)$ & $22(8.7)$ \\
\hline \multicolumn{4}{|l|}{ Sex } \\
\hline Male & $216(59)$ & $71(61)$ & $145(57)$ \\
\hline Female & $153(41)$ & $45(39)$ & $108(43)$ \\
\hline \multicolumn{4}{|l|}{ Race/Ethnicity } \\
\hline Non-Hispanic White & $206(56)$ & $60(52)$ & $146(58)$ \\
\hline Non-Hispanic Black & $111(30)$ & $33(28)$ & $78(31)$ \\
\hline Hispanic & $44(12)$ & $19(16)$ & $25(9.9)$ \\
\hline Non-Hispanic other & $8(2.2)$ & $4(3.5)$ & $4(1.6)$ \\
\hline \multicolumn{4}{|l|}{ Insurance coverage } \\
\hline Uninsured & $217(59)$ & $75(65)$ & $142(56)$ \\
\hline Public insurance & $121(33)$ & $7(6.0)$ & $90(36)$ \\
\hline Private insurance & $23(6.2)$ & $31(27)$ & $16(6.3)$ \\
\hline Other insurance ${ }^{a}$ & $8(2.2)$ & $3(2.6)$ & $5(2.0)$ \\
\hline \multicolumn{4}{|l|}{ Marital status } \\
\hline Single & $166(45)$ & $61(53)$ & $105(42)$ \\
\hline Married & $104(28)$ & $31(27)$ & $73(29)$ \\
\hline Separated/Divorced/Widowed & $99(27)$ & $24(21)$ & $75(30)$ \\
\hline \multicolumn{4}{|l|}{ Smoke intensity } \\
\hline$>1$ pack of cigarettes per day & $189(51)$ & $54(47)$ & $135(53)$ \\
\hline$\leq 1$ pack of cigarettes per day & $180(49)$ & $62(53)$ & $118(47)$ \\
\hline \multicolumn{4}{|l|}{ Alcohol consumption } \\
\hline Never drinker & $205(56)$ & $70(60)$ & $135(53)$ \\
\hline Current or former drinker & $164(44)$ & $46(40)$ & $118(47)$ \\
\hline \multicolumn{4}{|l|}{ Body Mass Index (BMI) } \\
\hline $\mathrm{BMI}<25$ & $133(36)$ & $47(41)$ & $86(34)$ \\
\hline $25 \leq \mathrm{BMI}<30$ & $96(26)$ & $22(19)$ & $74(29)$ \\
\hline $\mathrm{BMI} \geq 30$ & $140(38)$ & $47(41)$ & $93(37)$ \\
\hline \multicolumn{4}{|l|}{$\mathrm{NCl}$ comorbidity index score } \\
\hline 0 & $227(62)$ & $71(61)$ & $156(62)$ \\
\hline$>0$ & $142(38)$ & $45(39)$ & $97(38)$ \\
\hline \multicolumn{4}{|l|}{ SEER summary stage } \\
\hline Local & $210(57)$ & $60(52)$ & $150(59)$ \\
\hline Regional & $159(43)$ & $56(48)$ & $103(41)$ \\
\hline \multicolumn{4}{|l|}{ Cancer type } \\
\hline Smoking-related cancers (total) & $230(62)$ & $82(71)$ & $148(58)$ \\
\hline Lung/Bronchus/Trachea & $46(12)$ & $16(14)$ & $30(12)$ \\
\hline Colorectal & $40(11)$ & $19(16)$ & $21(8.3)$ \\
\hline
\end{tabular}


Table 1 Characteristics of adult cancer patients who were diagnosed with a first primary invasive non-metastatic solid malignancy between 2013 and 2015 and were smokers at baseline (Continued)

\begin{tabular}{llll}
\hline Characteristics & $\begin{array}{l}\text { All patients }(n=369) \\
n(\%)\end{array}$ & $\begin{array}{l}\text { Patients who quit within } 6 \text { months } \\
\text { of diagnosis }(n=116) \\
n(\%)\end{array}$ & $\begin{array}{l}\text { Patients who did not quit within } \\
6 \text { months of diagnosis }(n=253) \\
n(\%)\end{array}$ \\
\hline Oral/Pharynx/Larynx & $38(10)$ & $24(21)$ & $14(5.5)$ \\
Kidney/Ureter/Bladder & $37(10)$ & $9(7.8)$ & $28(11)$ \\
Liver & $33(8.9)$ & $5(4.3)$ & $28(11)$ \\
Pancreas & $13(3.5)$ & $3(2.6)$ & $10(4.0)$ \\
Cervix uteri & $12(3.3)$ & $1(0.86)$ & $11(4.3)$ \\
Esophagus/Stomach & $11(3.0)$ & $5(4.3)$ & $6(2.4)$ \\
Cancers not related to smoking (total) & $139(38)$ & $34(29)$ & $105(42)$ \\
Breast & $30(8.1)$ & $12(10)$ & $18(7.1)$ \\
Prostate & $24(6.5)$ & $3(2.6)$ & $21(8.3)$ \\
Other & $85(23)$ & $19(16)$ & $66(26)$ \\
Mortality by 3 years after diagnosis & $82(22)$ & $23(20)$ & $59(23)$ \\
Total follow-up time (person-years) & 428 & 153 & 275
\end{tabular}

${ }^{a}$ Other insurance included Tricare, Military, Veteran's affair, and Indian/Public health services

decisions about early smoking cessation. For example, one study [38] assessed the effect of recent cessation on overall survival among lung cancer patients who were treated with surgery. Recent cessation was defined as any time between cancer diagnosis and surgery, but the duration between diagnosis and surgery was not specified. More importantly, the results of prior studies are difficult to interpret as possible effects of smoking cessation because of misaligned time zero. Unlike RCTs, where time zero is well-defined, observational studies are sensitive to systematic errors that occur because of misaligned time zero. This misalignment occurs when

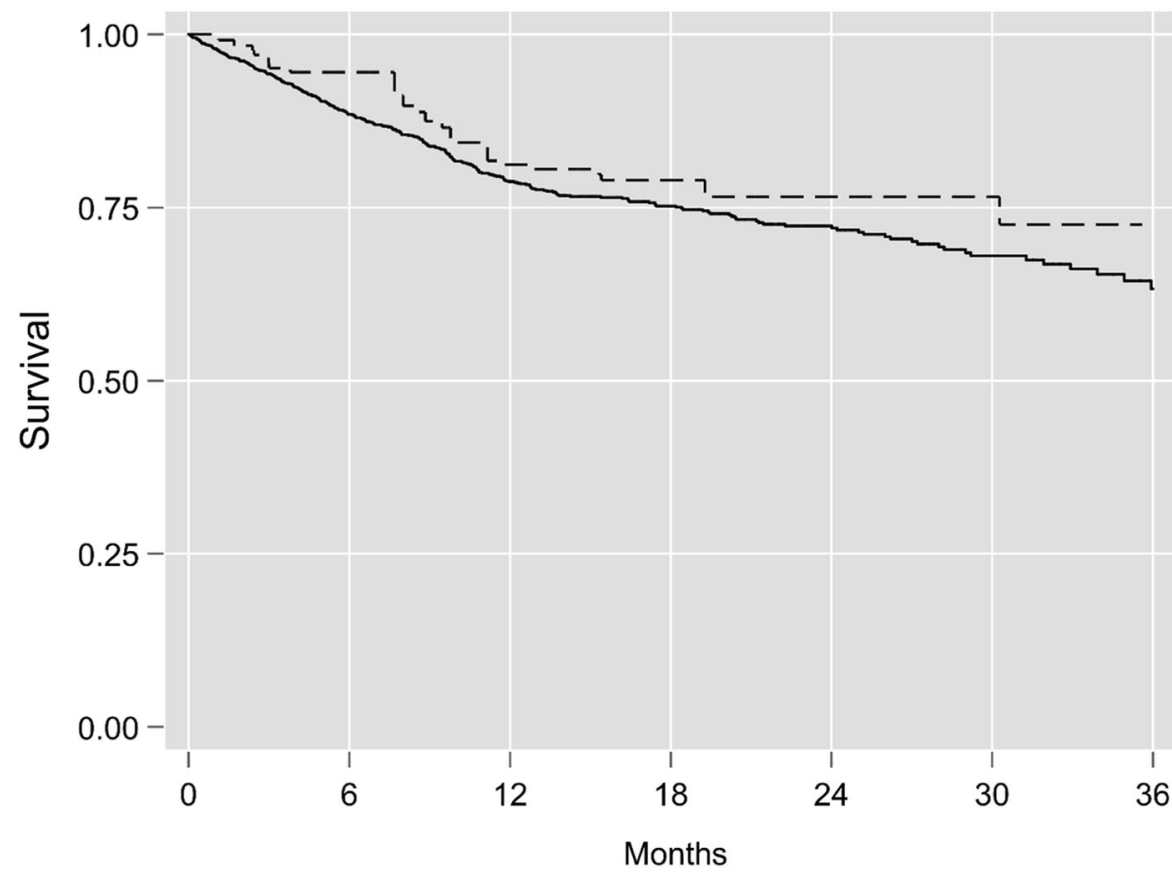

- Patients did not initiate smoking cessation within 6 months of cancer diagnosis

- - Patients initiated smoking cessation within 6 months of cancer diagnosis

Fig. 2 Marginal survival curves for cancer patients who initiated or did not initiate smoking cessation within 6 months of cancer diagnosis 
Table 2 Survival outcomes among cancer patients who initiated or did not initiate smoking cessation within 6 months of cancer diagnosis

\begin{tabular}{lll}
\hline & Estimate & $95 \% \mathrm{CL}^{\mathrm{a}}$ \\
\hline Restricted mean survival time given 3-year follow-up & & 26,33 months \\
Initiated smoking cessation & 30 months & 26,30 months \\
Did not initiate smoking cessation & 28 months & $-1.5,5.1$ months \\
Difference in RMST ${ }^{\text {b }}$ between initiators and non-initiators & 1.8 months & $0.097,0.43$ \\
Mortality risk by the end of 3-year follow-up & 0.26 & $0.25,0.48$ \\
Initiated smoking cessation & 0.37 & $0.37,1.4$ \\
Did not initiate smoking cessation & 0.72 & \\
Mortality risk ratio of quitters vs. non-quitters &
\end{tabular}

${ }^{a}$ Compatibility limits

${ }^{\mathrm{b}}$ Restricted mean survival time

eligibility, treatment (exposure) assignment, and follow-up do not occur simultaneously [14]. In particular, some studies used prevalent exposures, where smoking cessation occurred prior to eligibility or follow-up, which resulted in truncation of person-time contributed to the study $[38,41]$. Other studies assigned individuals as having quit smoking after eligibility and start of follow-up, which resulted in immortal time bias [37, 39, 40, 42]. The consequence can be severe bias away from the null. For example, one study [38] reported that the mortality hazard was 0.34 (95\% CL: 0.16, 0.71) times lower for recent cessation compared with continued smoking, which suggests more extreme effects on mortality than the 3-year mortality risk ratio of 0.72 (95\% CL: $0.37,1.4)$ observed in our study. Such overestimation related to misaligned time zero has been reported in other contexts [18]. In addition, duration of follow-up, frequency of smoking cessation, and population characteristics could contribute to differences between our study and prior studies.

Promotion of smoking cessation is an important part of a comprehensive treatment plan for cancer patients [43]. Despite the known benefits of cessation and the known risks of continuing to smoke, cancer diagnosis is underused [44] and undervalued [43] as an opportunity to promote cessation. Clinicians may have concerns that a cancer diagnosis is an inopportune time to discuss smoking because the patient is overwhelmed with significant life changes having received bad news and must manage and adhere to a new treatment regimen. Nevertheless, properly framed, a cancer diagnosis could be an educational opportunity to discuss the potential for improved outcomes with smoking cessation and support. Patients report a willingness to attempt cessation. For example, a recent study reported that cancer survivors

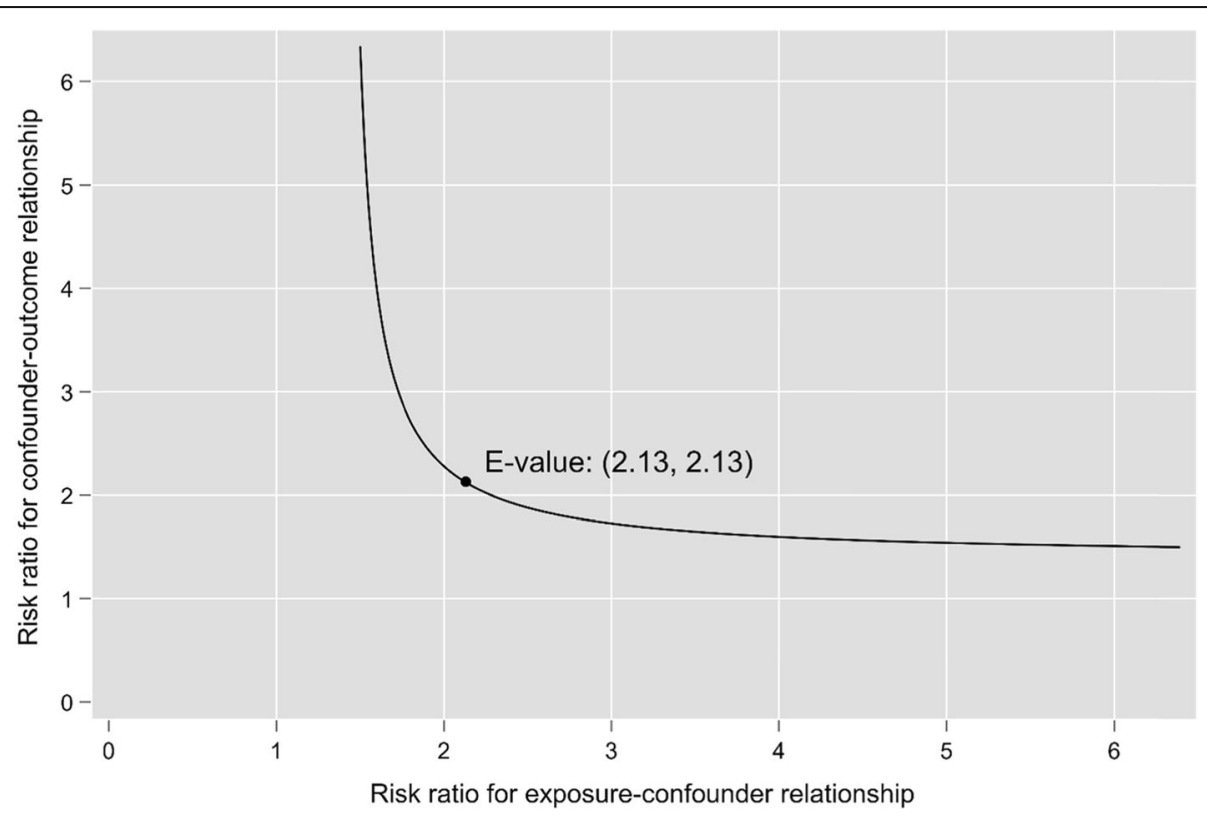

Fig. 3 E-value for the effect of smoking cessation within 6 months of cancer diagnosis on 3-year mortality among cancer patients 
who continued to smoke remained motivated to quit even beyond the initial diagnosis [45].

People diagnosed with cancer may have several barriers to smoking cessation. Cancer diagnosis generally occurs at older ages and people diagnosed with cancer may have a long history of smoking. The combination of many years of addiction and psychological distress from a cancer diagnosis can make smoking cessation challenging [46, 47]. Additionally, vulnerable populations, such as socioeconomically disadvantaged individuals, have a higher frequency of smoking and tobacco use [6], and have smoked for more years than those living above the poverty rate [48]. Such populations often rely on safetynet institutions for healthcare, including cancer treatment [21]. Despite higher frequency and heavier [49] smoking among underserved patients, safety-net institutions may have less resources to provide effective smoking cessation strategies such as groups and therapies.

\section{Conclusions}

In summary, smoking cessation is recommended for cancer survivors at any time during survivorship by the National Comprehensive Cancer Network [7], but unknown is the magnitude of benefit of early smoking cessation. Our results suggest that smoking cessation within 6 months of cancer diagnosis may increase survival, but the magnitude of effect is imprecise, which precludes definitive conclusions. Our results strengthen the available evidence by addressing limitations of prior analyses and improve understanding the potential interventional effects of early smoking cessation on a population level. Nevertheless, future studies with larger sample sizes that test the comparative effectiveness of different smoking cessation strategies are needed to provide more detailed evidence to inform decision-making. In addition, future studies should consider potential individual and structural barriers to implementing smoking cessation strategies, particularly in vulnerable populations.

\section{Supplementary information}

Supplementary information accompanies this paper at https://doi.org/10. 1186/s12885-020-07213-5.

Additional file 1: Supplementary Figure S1. Directed acyclic graph illustrating dependency assumptions for the effect of smoking cessation on cancer mortality. Supplementary Table S2. Distribution of observations related to eligibility changes across sequential trials.

\section{Abbreviations}

RMST: Restricted mean survival time; RR: Risk ratio; RCT: Randomized controlled trials; JPS: John Peter Smith (hospital name); BMl: Body mass index

\section{Acknowledgments}

The authors are grateful to Jeff Claassen for assistance with extracting data for this study from electronic health records.

\section{Authors' contributions}

TEB - conceptualization, investigation, project administration, writing original draft; YL - formal analysis, data curation, visualization, writing - review and editing; AG - investigation, writing - review and editing; BG - resources, writing - review and editing; RPO - methodology, formal analysis, supervision, writing - review and editing. All authors have read and approved the final manuscript

\section{Funding}

This research did not receive funding from agencies in the public, commercial, or not-for-profit sectors.

\section{Availability of data and materials}

The data analyzed for the current study are not publicly available to protect patient confidentiality but are available on reasonable request to the corresponding author and review by the JPS Health Network External Data Governance Committee.

Ethics approval and consent to participate

Ethical approval received by the North Texas IRB as an expedited protocol with informed consent waived (\#2017-19).

Consent for publication

Not applicable.

Competing interests

None of the authors have a conflict of interest.

\section{Author details}

${ }^{1}$ School of Public Health, University of North Texas Health Science Center, 3500 Camp Bowie Blvd., Fort Worth, TX 76107, USA. ${ }^{2}$ Center for Outcomes Research, JPS Health Network, 1500 S. Main Street, Fort Worth, TX 76104, USA. ${ }^{3}$ JPS Oncology and Infusion Center, JPS Health Network, 610 W. Terrell Ave., Fort Worth, TX 76104, USA. ${ }^{4}$ Department of Biostatistics and Epidemiology, University of North Texas Health Science Center, 3500 Camp Bowie Blvd., Fort Worth, TX 76107, USA.

Received: 13 January 2020 Accepted: 24 July 2020

Published online: 05 August 2020

\section{References}

1. Pang Q, Qu K, Zhang J, Xu X, Liu S, Song S, et al. Cigarette smoking increases the risk of mortality from liver cancer: a clinical-based cohort and meta-analysis. J Gastroenterol Hepatol. 2015;30(10):1450-60. https://doi.org/ 10.1111/jgh.12990.

2. Parsons A, Daley A, Begh R, Aveyard P. Influence of smoking cessation after diagnosis of early stage lung cancer on prognosis: systematic review of observational studies with meta-analysis. BMJ. 2010;340:b5569. https://doi. org/10.1136/bmj.b5569.

3. Islami F, Moreira DM, Boffetta P, Freedland SJ. A systematic review and meta-analysis of tobacco use and prostate cancer mortality and incidence in prospective cohort studies. Eur Urol. 2014;66(6):1054-64. https://doi.org/ 10.1016/j.eururo.2014.08.059.

4. Ordonez-Mena JM, Schottker B, Mons U, Jenab M, Freisling H, Bueno-deMesquita B, et al. Quantification of the smoking-associated cancer risk with rate advancement periods: meta-analysis of individual participant data from cohorts of the CHANCES consortium. BMC Med. 2016;14:62. https://doi.org/ 10.1186/s12916-016-0607-5.

5. Walter $V$, Jansen $L$, Hoffmeister $M$, Brenner $H$. Smoking and survival of colorectal cancer patients: systematic review and meta-analysis. Ann Oncol. 2014;25(8):1517-25. https://doi.org/10.1093/annonc/mdu040.

6. A Report of the Surgeon General. The Health Consequences of Smoking-50 Years of Progress. Atlanta: Reports of the Surgeon General; 2014.

7. Shields PG, Herbst RS, Arenberg D, Benowitz NL, Bierut L, Luckart JB, et al. Smoking cessation, version 1.2016, NCCN clinical practice guidelines in oncology. J Natl Compr Cancer Netw. 2016;14(11):1430-68.

8. Land SR, Toll BA, Moinpour CM, Mitchell SA, Ostroff JS, Hatsukami DK, et al. Research priorities, measures, and recommendations for assessment of tobacco use in clinical Cancer research. Clin Cancer Res. 2016;22(8):1907-13. https://doi.org/10.1158/1078-0432.CCR-16-0104. 
9. Warren GW, Marshall JR, Cummings KM, Toll B, Gritz ER, Hutson A, et al. Practice patterns and perceptions of thoracic oncology providers on tobacco use and cessation in cancer patients. J Thorac Oncol. 2013;8(5): 543-8. https://doi.org/10.1097/JTO.0b013e318288dc96.

10. Toll BA, Brandon TH, Gritz ER, Warren GW, Herbst RS, Tobacco ASo, et al. Assessing tobacco use by cancer patients and facilitating cessation: an American Association for Cancer Research policy statement. Clin Cancer Res. 2013;19(8):1941-8. https://doi.org/10.1158/1078-0432.CCR-13-0666.

11. Gritz ER, Toll BA, Warren GW. Tobacco use in the oncology setting: advancing clinical practice and research. Cancer Epidemiol Biomark Prev. 2014;23(1):3-9. https://doi.org/10.1158/1055-9965.EPI-13-0896.

12. Zeng L, Yu X, Yu T, Xiao J, Huang Y. Interventions for smoking cessation in people diagnosed with lung cancer. Cochrane Database Syst Rev. 2019;6: CD011751. https://doi.org/10.1002/14651858.CD011751.pub3.

13. Hernan MA, Robins JM. Using big data to emulate a target trial when a randomized trial is not available. Am J Epidemiol. 2016;183(8):758-64. https://doi.org/10.1093/aje/kwv254.

14. Hernan MA, Sauer BC, Hernandez-Diaz S, Platt R, Shrier I. Specifying a target trial prevents immortal time bias and other self-inflicted injuries in observational analyses. J Clin Epidemiol. 2016;79:70-5. https://doi.org/10. 1016/j.jclinepi.2016.04.014.

15. Danaei G, Rodriguez LA, Cantero OF, Logan R, Hernan MA. Observational data for comparative effectiveness research: an emulation of randomised trials of statins and primary prevention of coronary heart disease. Stat Methods Med Res. 2013;22(1):70-96. https://doi.org/10.1177/ 0962280211403603.

16. Hernan MA, Alonso A, Logan R, Grodstein F, Michels KB, Willett WC, et al. Observational studies analyzed like randomized experiments: an application to postmenopausal hormone therapy and coronary heart disease. Epidemiology. 2008;19(6):766-79. https://doi.org/10.1097/EDE. Ob013e3181875e61.

17. Lodi S, Phillips A, Lundgren J, Logan R, Sharma S, Cole SR, et al. Effect estimates in randomized trials and observational studies: comparing apples with apples. Am J Epidemiol. 2019. https://doi.org/10.1093/aje/kwz100.

18. Danaei G, Tavakkoli M, Hernan MA. Bias in observational studies of prevalent users: lessons for comparative effectiveness research from a meta-analysis of statins. Am J Epidemiol. 2012;175(4):250-62. https://doi.org/10.1093/aje/kwr301.

19. Adler NE, Newman K. Socioeconomic disparities in health: pathways and policies. Health Aff (Millwood). 2002;21(2):60-76. https://doi.org/10.1377/ hlthaff.21.2.60.

20. Andrulis DP. Access to care is the centerpiece in the elimination of socioeconomic disparities in health. Ann Intern Med. 1998;129(5):412-6.

21. Lewin $\mathrm{E}$, Altman $\mathrm{S}$. America's health care safety net: intact but endangered. Washington (DC): National Academies Press (US); 2000.

22. Robins JM, Hernan MA, Brumback B. Marginal structural models and causal inference in epidemiology. Epidemiology. 2000;11(5):550-60.

23. Andersen PK, Syriopoulou E, Parner ET. Causal inference in survival analysis using pseudo-observations. Stat Med. 2017;36(17):2669-81. https://doi.org/ 10.1002/sim.7297.

24. Andersen PK, Perme MP. Pseudo-observations in survival analysis. Stat Methods Med Res. 2010;19(1):71-99. https://doi.org/10.1177/ 0962280209105020.

25. Royston P, Parmar MK. Restricted mean survival time: an alternative to the hazard ratio for the design and analysis of randomized trials with a time-toevent outcome. BMC Med Res Methodol. 2013;13:152. https://doi.org/10. 1186/1471-2288-13-152.

26. Saad ED, Zalcberg JR, Peron J, Coart E, Burzykowski T, Buyse M. Understanding and communicating measures of treatment effect on survival: can we do better? J Natl Cancer Inst. 2018;110(3):232-40. https:// doi.org/10.1093/jnci/djx179.

27. Weir IR, Marshall GD, Schneider Jl, Sherer JA, Lord EM, Gyawali B, et al. Interpretation of time-to-event outcomes in randomized trials: an online randomized experiment. Ann Oncol. 2019;30(1):96-102. https://doi.org/10. 1093/annonc/mdy462.

28. Murray EJ, Caniglia EC, Swanson SA, Hernandez-Diaz S, Hernan MA. Patients and investigators prefer measures of absolute risk in subgroups for pragmatic randomized trials. J Clin Epidemiol. 2018;103:10-21. https://doi. org/10.1016/j.jclinepi.2018.06.009.

29. Cole SR, Hernan MA. Constructing inverse probability weights for marginal structural models. Am J Epidemiol. 2008;168(6):656-64. https://doi.org/10. 1093/aje/kwn164.
30. Center for Disease Control and Prevention. Smoking and Cancer. https:// www.cdc.gov/tobacco/data_statistics/sgr/50th-anniversary/pdfs/wynkcancer.pdf. Accessed 04/08/2019.

31. National Cancer Institute. NCl Comorbidity Index Overview. https:// healthcaredelivery.cancer.gov/seermedicare/considerations/comorbidity. html. Accessed 12/18/2018.

32. Amrhein V, Greenland S, McShane B. Scientists rise up against statistical significance. Nature. 2019;567(7748):305-7. https://doi.org/10.1038/d41586019-00857-9.

33. VanderWeele TJ, Ding P. Sensitivity analysis in observational research: introducing the E-value. Ann Intern Med. 2017;167(4):268-74. https://doi. org/10.7326/M16-2607.

34. Warren GW. Mitigating the adverse health effects and costs associated with smoking after a cancer diagnosis. Transl Lung Cancer Res. 2019;8(Suppl 1): S59-66. https://doi.org/10.21037/t|cr.2019.04.07.

35. Greenland S, Robins JM. Identifiability, exchangeability, and epidemiological confounding. Int J Epidemiol. 1986;15(3):413-9. https://doi.org/10.1093/ije/ 15.3.413.

36. Cole SR, Frangakis CE. The consistency statement in causal inference: a definition or an assumption? Epidemiology. 2009;20(1):3-5. https://doi.org/ 10.1097/EDE.0b013e31818ef366.

37. Dobson Amato KA, Hyland A, Reed R, Mahoney MC, Marshall J, Giovino G, et al. Tobacco cessation may improve lung Cancer patient survival. J Thorac Oncol. 2015;10(7):1014-9. https://doi.org/10.1097/JTO.0000000000000578.

38. Sardari Nia P, Weyler J, Colpaert C, Vermeulen P, Van Marck E, Van Schil P. Prognostic value of smoking status in operated non-small cell lung cancer. Lung Cancer. 2005;47(3):351-9. https://doi.org/10.1016/j.lungcan.2004.08.011.

39. Roach MC, Rehman S, DeWees TA, Abraham CD, Bradley JD, Robinson CG. It's never too late: smoking cessation after stereotactic body radiation therapy for non-small cell lung carcinoma improves overall survival. Pract Radiat Oncol. 2016;6(1):12-8. https://doi.org/10.1016/j.prro.2015.09.005.

40. Koshiaris C, Aveyard P, Oke J, Ryan R, Szatkowski L, Stevens R, et al. Smoking cessation and survival in lung, upper aero-digestive tract and bladder cancer: cohort study. Br J Cancer. 2017;117(8):1224-32. https://doi.org/10. 1038/bjc.2017.179.

41. Warren GW, Kasza KA, Reid ME, Cummings KM, Marshall JR. Smoking at diagnosis and survival in cancer patients. Int J Cancer. 2013;132(2):401-10. https://doi.org/10.1002/ijc.27617.

42. Hawari Fl, Obeidat NA, Rimawi D, Jamal K. Smoking cessation care can translate to lower hazard of death in the short-run in cancer patients - a retrospective cohort study to demonstrate the value of smoking cessation services within the treatment phase of cancer. BMC Cancer. 2019;19(1):580. https://doi.org/10.1186/s12885-019-5778-y.

43. Jassem J. Tobacco smoking after diagnosis of cancer: clinical aspects. Transl Lung Cancer Res. 2019;8(Suppl 1):S50-S8. https://doi.org/10.21037/tlcr.2019.04.01.

44. Gritz ER, Fingeret MC, Vidrine DJ, Lazev AB, Mehta NV, Reece GP. Successes and failures of the teachable moment: smoking cessation in cancer patients. Cancer. 2006;106(1):17-27. https://doi.org/10.1002/cncr.21598.

45. Paul CL, Tzelepis F, Boyes AW, D'Este C, Sherwood E, Girgis A. Continued smoking after a cancer diagnosis: a longitudinal study of intentions and attempts to quit. J Cancer Surviv. 2019;13(5):687-94. https://doi.org/10.1007/ s11764-019-00787-5.

46. Schnoll RA, Rothman RL, Wielt DB, Lerman C, Pedri H, Wang H, et al. A randomized pilot study of cognitive-behavioral therapy versus basic health education for smoking cessation among cancer patients. Ann Behav Med. 2005;30(1):1-11. https://doi.org/10.1207/s15324796abm3001_1.

47. Gritz ER, Vidrine DJ, Fingeret MC. Smoking cessation a critical component of medical management in chronic disease populations. Am J Prev Med. 2007; 33(6 Suppl):S414-22. https://doi.org/10.1016/j.amepre.2007.09.013.

48. Siahpush M, Singh GK, Jones PR, Timsina LR. Racial/ethnic and socioeconomic variations in duration of smoking: results from 2003, 2006 and 2007 tobacco use supplement of the current population survey. J Public Health (Oxf). 2010;32(2):210-8.

49. Ham DC, Przybeck T, Strickland JR, Luke DA, Bierut L, Evanoff BA. Occupation and workplace policies predict smoking behaviors: analysis of national data from the current population survey. J Occup Environ Med. 2011;53(11):1337-45.

\section{Publisher's Note}

Springer Nature remains neutral with regard to jurisdictional claims in published maps and institutional affiliations. 